\title{
USAGE OF POLCAM DEVICE FOR PARAMETER MONITORING AND TRAFFIC FLOW MODELLING
}

This article deals with a proposal of using the Polcam PC2006 device for obtaining the traffic flow characteristics. This device is a first of a kind at the University of Zilina. The aim was to perform a practical measurement with a floating vehicle on a selected road section I/18 Zilina - Strecno - Vrutky, evaluate basic characteristics of a traffic flow with consequent modelling and use of software tools. Three measurements were performed in road traffic under different conditions. Individual calculations based on data obtained from practical measurements are processed at the end of the article. The results obtained from the measurement are used for traffic flow modelling in the programme Aimsun.

Keywords: Traffic flow, traffic modelling, Polcam PC2006 device, intensity, density, speed.

\section{Introduction}

Traffic modelling using software equipment presents a forceful working method in traffic engineering area. Traffic flow simulation models were created as a tool for theoretical study of different factors of analysed values of basic traffic characteristics. Specialised software products are being used presently for traffic problems solving, as these have excessive possibilities of simulations and settings. They enable us to simulate numerous scenarios of traffic infrastructure in short time period. By using the simulation it is possible to model current and future statuses of traffic for the respective traffic flow [1].

\section{Traffic flow movement}

Traffic flow is defined as a movement of vehicles (pedestrians) in one line or in parallel lanes in the same direction. It can consist of several driving (walking) lanes, and has its characteristics and specific features, which describe its movement under different conditions.

During the drive the situation is being changed continuously and complicated situations arise as the influences of road users, time, space and movement take effect. Vehicles have influence on other vehicles during movement both in line and parallel, move in groups and make use of their speed. Their movement is determined not only by the abilities and requirements of users, vehicles' performance, vehicles' number and types, but also by road parameters, surroundings and climate conditions. Traffic flow consists of all flow participants moving in line or in parallel in the same traffic direction. It can consist of one or more traffic lanes. Vehicles moving in traffic lane change their position in time [2].

\subsection{Traffic flow characteristics}

Basic characteristics of traffic lane, describing its quantity and quality, are:

- intensity,

- speed,

- density.

Indirect characteristics of traffic flow are:

- time gap,

- length gap among individual vehicles [2].

\section{Monitored section characteristics}

For the practical measurement a road section of I/18 Zilina Strecno - Vrutky was chosen. It ranks among the most frequently used road sections in Slovakia. Based on the analysis of average daily traffic densities it is possible to figure out the growing traffic intensity on this section of road I/18. For comparison, in the year 2000 the intensity on entrance to the town of Vrutky was 14,784 vehicles, in the year 2010 it was already 25,463 vehicles, which

\footnotetext{
* Jan Ondrus, Lubomir Cernicky

Department of Road and Urban Transport, Faculty of Operation and Economics of Transport and Communications, University of Zilina, Slovakia E-mail: jan.ondrus@fpedas.uniza.sk
} 
presents an increase by 10679 vehicles. The specified road section $\mathrm{I} / 18$ has a length of $16.444 \mathrm{~km}$. The starting point set by the mile post is at $460.745 \mathrm{~km}$, by the offset to Dubravy [3].

Then the road leads through the part called Mojsova Lucka, followed by Strecno. After passing through Strecno municipality it follows the river Vah up to the section Dubna Skala. The section ending point is set by the mile post at $477.189 \mathrm{~km}$ onto the I. class road at the entrance to the town of Vrutky. The width of the road in the specified section is between $9 \mathrm{~m}-14 \mathrm{~m}$. The overall section is pictured in Fig. 1.

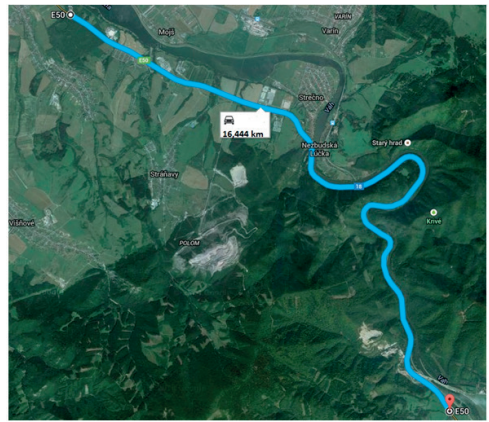

Fig. 1 I/18 road section map [4]

The owner of the road is the state and the administrator is the Slovak Road Administration Office. The respective road does not fulfil the requirements for safe and fluent road traffic due to following factors: construction, equipment, road surface, as well as placement in the surroundings.

\section{Description of measurement technology}

As a part of the operational programme Research and Development, project: Centre of excellence for systems and services of intelligent transport II, the Polcam PC2006, a device for traffic flow parameter monitoring, was obtained in the year 2014. This device was installed into a laboratory vehicle Citroen C6 3,0i V6 BVA, belonging to laboratories of the Department of Road and Urban Transport, Faculty of Operations and Economics of Transport and Communications at the University of Zilina (Fig. 2).
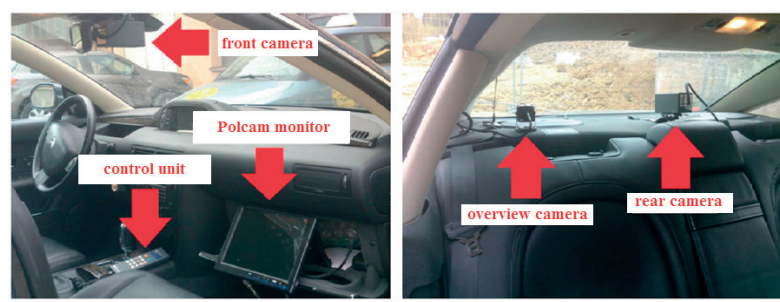

Fig. 2 Polcam PC2006 system installed in the vehicle [authors]
The mobile system Polcam PC2006 is a device designed to patrol the road traffic situation, exact measurement and average vehicle speed of the vehicle in which it is installed. It is designed for indirect measurement of the vehicle speed in front of, or behind the vehicle, in which the system is installed. The respective measurement is based on time measuring and passed distance. The system measures the average speed based on the exact measurement of distance and time.

The system Polcam PC2006 consists of:

- Polcam control unit,

- Remote control,

- Display unit Polcam EC-M (optional 7"-10“ monitor),

- 28 x zoom camera Polcam EC-C (C28E) [5].

To these basic Polcam PC2006 components other additional equipment is connected:

- Digital registering equipment with HDD up to 320 GB and 4 to 8 inputs of format H.264,

- Cable system (connection of individual parts of the system and installation on the vehicle),

- Overview wide-angle cameras VS,

- GSM and WiFi antenna,

- Wireless equipment for sound transfer.

The control unit is connected by cable system with individual parts of the road speed meter, to power from the dashboard and screening of the vehicle speed [5].

The control unit fulfils the following functions:

- measures distance and time and from these data calculates the average speed,

shows the video inputs and measured data on the monitor, processes measured data and controls auxiliary equipment.

The control unit calculates the distance from data obtained from an ABS sensor, or from vehicle data collector CAN BUS. Based on these data - sensor equipment impulses, a constant is set (number of impulses on a precisely set track, usually 500 to $1000 \mathrm{~m}$ ) to calculate an instantaneous speed. For synchronization of wheel perimeter and the track passed, the central unit has a possibility of changing the constant due to wheel dimension of individual vehicles (a constant of road speedometer is the number of impulses $k i$ on a formerly set out and passed track $k d$ [5].

The setting up and check of the constant of road speedometer is being done during official validation of the Polcam PC2006 system. During validation the value of distance (track) $k d$ and number of impulses on the passed distance $k i$, are inserted into the central unit memory of the road speedometer, inserting is being done by a procedure specified by the manufacturer.

All information displayed on the screen is being saved on a hard disc of the recording equipment. Following pieces of information are continuously displayed on the monitor of the measuring device: date, time, camera identification /arrival, 
departure/, camera zoom, number of photos, distance passed, instantaneous vehicle speed, number of impulses, firmware number, equipment manufacturing number, identification of the equipment, control links for measured vehicle picture size assessment, and data from other optional additional equipment [5].

The system Polcam PC2006 can also be equipped with additional systems and equipment for:

- speed measuring - speed measuring of the vehicle while driving and stationary (radar),

speed measuring - speed measuring of vehicles on standby and measuring distance when stopping (laser),

- ANPR (Automatic Number Plate Recognition) - system for automatic plate numbers recognition.

\section{Processing of the measured data}

For the processing of results acquired from the measuring device Polcam PC2006 the programme Polcam Playback was used.

It is used to playback, edit and evaluate the records, preparation of speed measuring proofs, or for other regulation breaks in road traffic. The programme Polcam Playback is connected to Google maps, in particular with Google Street View. The advantage of this connection is a $3 \mathrm{D}$ projection of the respective road section (Fig. 3).

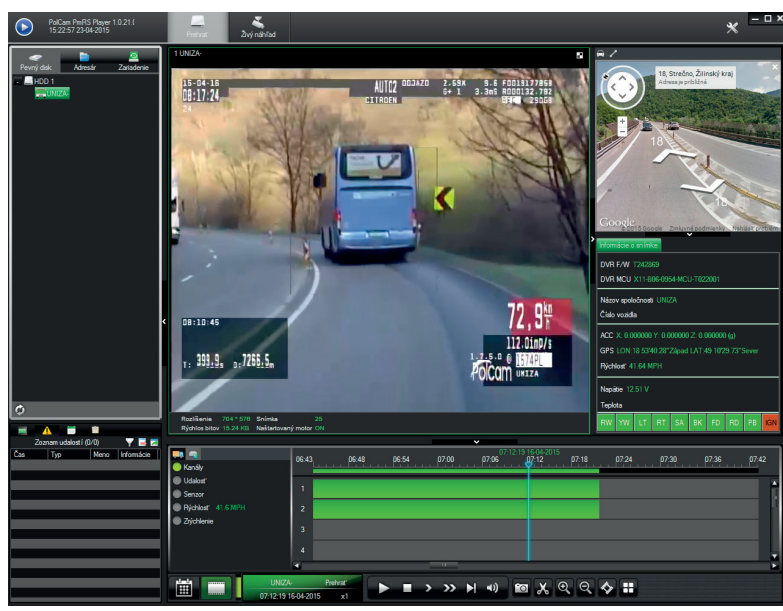

Fig. 3 SW Polcam Playback connected with Google Street View

\section{Measured and calculated parameters}

Section monitoring measured by a floating vehicle is sometimes named a Floating vehicle method. A measured track is divided into partial sections, as homogenous as possible from the construction point of view, as well as usage and traffic load.
6.1. Values obtained by practical measurement

Three measurements were done - morning peak hour, saddle, and afternoon peak hour.

- morning peak hour - measurement performed on April 16, 2015

- direction Zilina - Vrutky: start 7:48:21, finish 8:03:03

- direction Vrutky - Zilina: start 8:05:38, finish 8:19:53

- saddle - measurement performed on March 30, 2015

- direction Zilina - Vrutky: start 12:48:23, finish 13:00:30

- direction Vrutky - Zilina: start 13:01:58, finish 13:14:47

- afternoon peak hour - measurement performed on April 20, 2015

- direction Zilina - Vrutky: start 16:00:17, finish 16:13:03

- direction Vrutky - Zilina: start 16:14:06, finish 16:27:56

\section{Measurement method}

During the execution of a measurement with the use of a floating vehicle, firstly the vehicle moves in the direction of the measured section of the traffic flow, then in the opposite direction. In both cases measurements and numbers of overtaken and overtaking vehicles are being recorded. When driving back, the vehicles driving in opposite direction are being counted. In our particular measurement the number of vehicles passing (passed) in the same direction was zero.

Intensities (M) obtained by practical measurements were recalculated into hours. Individual intensities are shown in the following Table 1. Only the saddle case is shown.

Traffic flow intensities for the saddle

Table 1

\begin{tabular}{|c|c|c|c|}
\hline \multirow{4}{*}{ DIRECTION } & \multicolumn{2}{|c|}{ Zilina - Vrutky } \\
\cline { 2 - 4 } & Vehicle type & $\begin{array}{c}\text { Intensity obtained } \\
\text { by measurement }\end{array}$ & $\begin{array}{c}\text { Intensity converted } \\
\text { to hours }\end{array}$ \\
\hline Personal vehicles & 219 & 504 \\
\hline Trucks & 12 & 28 \\
\hline Buses & 2 & 5 \\
\hline Truck semitrailers & 47 & 108 \\
\hline Total & 280 & 645 \\
\hline \multirow{7}{*}{ DIRECTION } & \multicolumn{2}{|c|}{ Vrutky - Zilina } \\
\cline { 2 - 4 } & Vehicle type & $\begin{array}{c}\text { Intensity obtained } \\
\text { by measurement }\end{array}$ & $\begin{array}{c}\text { Intensity converted } \\
\text { to hours }\end{array}$ \\
\cline { 2 - 4 } & Personal vehicles & 174 & 401 \\
\hline Trucks & 23 & 53 \\
\hline Buses & 1 & 2 \\
\hline Truck semitrailers & 53 & 123 \\
\hline Total & 251 & 579 \\
\hline
\end{tabular}

\section{Section speed $\left(\mathrm{V}_{\mathrm{u}}\right)$}

Section speed was obtained from Polcam device, which evaluated the respective section upon measurement completion. 
Maximum distance, $9999.9 \mathrm{~m}$, is predefined in Polcam device. After exceeding this distance we continued the measurement after repeatedly pressing the START/STOP button. When calculating the section speed we used the weighted arithmetic average (Table 2).

\section{Density (H)}

Model calculation for saddle is shown below as an example. Density is calculated based on the formula below:

$H=\frac{M}{V_{u}}$

Overview of basic characteristics for "saddle period" is in the following Table 2.

Basic characteristics overview

Table 2

\begin{tabular}{|c|c|c|c|c|}
\hline \multicolumn{5}{|c|}{ Measurement } \\
\hline \multirow{16}{*}{ 莺 } & \multicolumn{2}{|c|}{ Measurement time } & \multicolumn{2}{|c|}{13 minutes 49 seconds } \\
\hline & \multicolumn{2}{|c|}{ Measurement direction } & \multicolumn{2}{|c|}{ Zilina - Vrutky } \\
\hline & Vehicle type & Intensity - M & $\begin{array}{c}\text { Section } \\
\text { speed } \\
(\mathrm{km} / \mathrm{h})\end{array}$ & $\begin{array}{c}\text { Density } \\
\text { (vehicle/km) }\end{array}$ \\
\hline & Personal vehicles & 506 & \multirow{5}{*}{76.22} & \multirow{5}{*}{8.46} \\
\hline & Trucks & 27 & & \\
\hline & Buses & 4 & & \\
\hline & Truck semitrailers & 108 & & \\
\hline & Total & 645 & & \\
\hline & \multicolumn{2}{|c|}{ Measurement time } & \multicolumn{2}{|c|}{12 minutes 7 seconds } \\
\hline & \multicolumn{2}{|c|}{ Measurement direction } & \multicolumn{2}{|c|}{ Vrutky - Zilina } \\
\hline & Vehicle type & Intensity - M & $\begin{array}{c}\text { Section } \\
\text { speed } \\
(\mathrm{km} / \mathrm{h})\end{array}$ & $\begin{array}{c}\text { Density } \\
\text { (vehicle/km) }\end{array}$ \\
\hline & Personal vehicles & 402 & \multirow{5}{*}{81.39} & \multirow{5}{*}{7.11} \\
\hline & Trucks & 53 & & \\
\hline & Buses & 2 & & \\
\hline & Truck semitrailers & 122 & & \\
\hline & Total & 579 & & \\
\hline
\end{tabular}

\section{The use of results for the purpose of traffic flow modelling}

\subsection{SW Aimsun}

To verify and evaluate the actual state, the respective road section I/18 was modelled in the programme Aimsun. This programme enables both macroscopic and microscopic simulation. Input parameters for modelling were obtained from practical measurement.

Traffic model, created in such a way as to represent the real situation in the respective section to the most possible extent, is based on traffic net. Matrixes for all types of traffic were created. Although the road is predominantly used by personal vehicles, there are also trucks and buses on it. The model was created in the time period of morning peak hour, afternoon peak hour, and saddle [1].

The model is based on a map imported into the programme from a map database Open Street Map. Gradually the lines of individual communications were created, connected in joints in the spots where in the reality cross-roads are situated.

During modelling the focus was put on the true resemblance of all items of net, and maximum permitted speeds and lanes structure were taken into account. An identical model of the existing status was created, which, after filling with values, can be considered reliable. To create the modelling the supporting information from maps was used, mainly for obtaining the distances measurements, which in real traffic would be very difficult to measure.

\section{The model load}

After communication model creation it was possible to start with model loading. Loading of traffic model was done based on a practical measurement performed by the floating vehicle, equipped with the Polcam device. Values of all intensities were inserted into matrixes in programme Aimsun and the traffic model was loaded with them.

\subsection{Data obtained from the model}

We compared the data obtained from the traffic model with the data obtained by the practical measurement. Individual measurements were divided into morning peak hour, afternoon peak hour and saddle. A 30 minutes heating up was predefined in traffic model. All calculations and values in the tables were calculated by the authors themselves.

\section{Intensity}

Individual intensities, evaluated by the traffic model, copy the intensities obtained by a practical measurement, which shows that the respective traffic model mirrors the real conditions on the road. In most cases the intensities obtained by the practical measurement were a bit higher compared to the model (Table 3). 
Intensity (vehicle)

\begin{tabular}{|c|c|c|c|}
\hline \multirow{4}{*}{ DIRECTION } & \multicolumn{2}{|c|}{ Zilina - Vrutky } \\
\hline \multirow{7}{*}{$\begin{array}{c}\text { Intensity } \\
\text { obtained by } \\
\text { traffic model }\end{array}$} & $\begin{array}{c}\text { Intensity obtained by } \\
\text { measurement }\end{array}$ \\
\hline Personal vehicles & 513 & 504 \\
\hline Trucks & 29 & 28 \\
\hline Buses & 3 & 5 \\
\hline Truck semitrailers & 102 & 108 \\
\hline Total & 647 & 645 \\
\hline DIRECTION & \multicolumn{2}{|c|}{ Vrutky - Zilina } \\
\hline Vehicle type & $\begin{array}{c}\text { Intensity } \\
\text { obtained by } \\
\text { traffic model }\end{array}$ & $\begin{array}{c}\text { Intensity obtained by } \\
\text { measurement }\end{array}$ \\
\hline Personal vehicles & 385 & \multicolumn{2}{|c|}{401} \\
\hline Trucks & 74 & 53 \\
\hline Buses & 3 & 2 \\
\hline Truck semitrailers & 110 & 123 \\
\hline Total & 572 & 579 \\
\hline
\end{tabular}

\section{The delay time}

Out of the data provided by the traffic model we picked the delay time as a next parameter. In the following Table 4 the delay times for sections Zilina - Vrutky and Vrutky - Zilina are shown. Delay times are stated for individual vehicle types. The delay was calculated as the average of individual replications of the traffic model. Out of the individual replications the delay times of vehicles on traffic model were set. Delay time of vehicles in traffic model was influenced by the position of individual vehicle types in traffic line.

Vehicles delay time in traffic model

Table 4

\begin{tabular}{|c|c|c|}
\hline Saddle & \multicolumn{2}{|c|}{ Delay time (s) } \\
\hline Vehicle type & Zilina - Vrutky & Vrutky - Zilina \\
\hline Personal vehicles & 151.60 & 137.37 \\
\hline Trucks & 71.01 & 66.53 \\
\hline Buses & 78.34 & 74.87 \\
\hline Truck semitrailers & 70.17 & 64.27 \\
\hline
\end{tabular}

\section{$\mathrm{CO}_{2}$ emissions}

The programme Aimsun based on the Panis model recalculates the $\mathrm{CO}_{2}$ emissions released by the vehicles in the traffic model. The $\mathrm{CO}_{2}$ emissions are shown in grams. The emissions are stated for the individual types of vehicles released during a morning peak hour, an afternoon peak hour and a saddle. The highest amount of emissions was produced during the morning peak hour on the road section Vrutky - Zilina. Out of the individual vehicle types the highest amount of emissions was produced during the morning peak hour in the section Vrutky - Zilina by personal vehicles. The lowest emissions reached were in the section Vrutky - Zilina produced by busses. The overall lowest produced emissions were reached in section Zilina - Vrutky during the morning peak hour. The $\mathrm{CO}_{2}$ emissions are in the following Table 5 stated in grams.

$\mathrm{CO}_{2}$ emissions

Table 5

\begin{tabular}{|c|c|c|}
\hline Saddle & \multicolumn{2}{|c|}{ Emissions $_{\mathbf{C O}_{2}} \mathbf{( g )}$} \\
\hline Vehicle type & Zilina - Vrutky & Vrutky - Zilina \\
\hline Personal vehicles & 66924.66 & 574694.85 \\
\hline Trucks & 103239.30 & 97005.35 \\
\hline Buses & 7008.03 & 13719.18 \\
\hline Truck semitrailers & 131917.71 & 268255.02 \\
\hline Total & $\mathbf{9 1 1 ~ 4 1 2 . 7 0}$ & $\mathbf{9 5 3 6 7 4 . 4 0}$ \\
\hline
\end{tabular}

\section{The section speed}

To draw a comparison we herewith state section speeds obtained from the traffic model and the ones obtained from the practical measurement. The section speeds obtained from the traffic model were evaluated for the individual types of vehicles. In case of the measurement we obtained section speed data only for the individual sections (Zilina - Vrutky / Vrutky - Zilina). Section speed of the traffic model and practical measurement can be compared by comparison of average section speed of the traffic model $(76.58 \mathrm{~km} / \mathrm{h})$ and section speed evaluated from the measurement $(76.22 \mathrm{~km} / \mathrm{h})$; see Table 6 .

Section speed $(\mathrm{km} / \mathrm{h})$

Table 6

\begin{tabular}{|c|c|c|c|c|}
\hline Saddle & $\begin{array}{l}\text { Traffic } \\
\text { model }\end{array}$ & Measurement & $\begin{array}{l}\text { Traffic } \\
\text { model }\end{array}$ & Measurement \\
\hline Vehicle type & $\begin{array}{l}\text { Zilina - } \\
\text { Vrutky }\end{array}$ & $\begin{array}{l}\text { Zilina - } \\
\text { Vrutky }\end{array}$ & $\begin{array}{l}\text { Vrutky - } \\
\text { Zilina }\end{array}$ & Vrutky - Zilina \\
\hline $\begin{array}{l}\text { Personal } \\
\text { vehicles }\end{array}$ & 76.91 & \multirow{5}{*}{76.22} & 78.4 & \multirow{5}{*}{81.39} \\
\hline Trucks & 75.68 & & 76.42 & \\
\hline Buses & 76.58 & & 76.43 & \\
\hline $\begin{array}{c}\text { Truck } \\
\text { semitrailers }\end{array}$ & 75.67 & & 76.53 & \\
\hline $\begin{array}{l}\text { Average } \\
\text { value }\end{array}$ & 76.58 & & 76.58 & \\
\hline
\end{tabular}

\section{The density}

The density of the traffic flow obtained from both traffic model and the practical measurement reached similar values. Different aspects, such as section speed obtained from evaluation device Polcam PC2006 and traffic flow intensity, influenced the density in the traffic model (Table 7). With growing traffic flow 
intensity also the density grew, and, on the contrary, with growing section speed the density dropped.

Density (vehicle/km)

\begin{tabular}{|c|c|c|c|c|}
\hline Saddle & $\begin{array}{l}\text { Traffic } \\
\text { model }\end{array}$ & Measurement & $\begin{array}{l}\text { Traffic } \\
\text { model }\end{array}$ & Measurement \\
\hline Vehicle type & $\begin{array}{l}\text { Zilina - } \\
\text { Vrutky }\end{array}$ & $\begin{array}{l}\text { Zilina - } \\
\text { Vrutky }\end{array}$ & $\begin{array}{c}\text { Vrutky - } \\
\text { Zilina }\end{array}$ & $\begin{array}{c}\text { Vrutky - } \\
\text { Zilina }\end{array}$ \\
\hline $\begin{array}{l}\text { Personal } \\
\text { vehicles }\end{array}$ & 7 & \multirow{5}{*}{8} & 5 & \multirow{5}{*}{7} \\
\hline Trucks & 1 & & 1 & \\
\hline Buses & 0 & & 0 & \\
\hline $\begin{array}{c}\text { Truck } \\
\text { semitrailers }\end{array}$ & 1 & & 2 & \\
\hline Average value & 9 & & 8 & \\
\hline
\end{tabular}

\section{Conclusion}

Traffic modelling with the use of information technologies (IT) represents a powerful working method in the field of Traffic engineering. This broadens the possibilities of complex task and problem solving. The Traffic modelling included not only the traffic simulation, but a broad scale of assisting tools, from simple, single-purpose applications, to complex tools for proposing and verification of the communication networks. The results obtained from traffic model are nowadays considered to be sufficiently reliable and relevant and they create base for reviewing current state of basic characteristics in the traffic flow. The outcomes from the traffic model can be used at different stages of urban planning and development, as well as for the evaluation of impact on particular solutions of traffic situations in the respective system.

In the traffic model we created, also the environmental influences of vehicles were considered.

\section{Acknowledgements}

This contribution is the result of the project implementation: Centre of excellence for systems and services of intelligent transport, ITMS 26220120028 supported by the Research \& Development Operational Programme funded by the ERDF.

\section{References}

[1] GOGOLA, M.: Applications of Methodology of Calculation of the Number of Connections (MCNC) in Solving Transport Attendance, Communications - Scientific Letters of the University of Zilina, No. 2, 2005, pp. 17-19. ISSN 1335-4205.

[2] KALASOVA, A., FAITH, P., PALO, J.: Traffic Engineering 1: Organization and Traffic Management, EDIS : University of Zilina, 2006, 194 p., ISBN 80-8070-634-4.

[3] http://www.zask.sk/sk/samosprava/urad-zsk/odbor-dopravy-regionalnehorozvoja/

doprava/vseobecne-informacie-doprave-zilinskom-kraji.html.

[4] https://www.google.sk/maps.

[5] Internal documents of ZTS Elektronika SKS s.r.o. 